\title{
Multiscale computer model of the spinal dorsal horn reveals changes in network processing
} associated with chronic pain

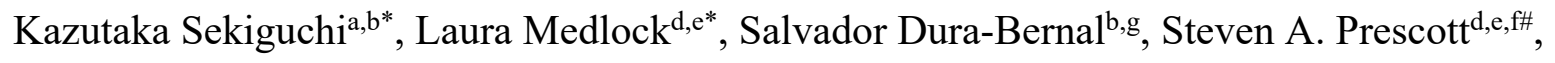
William W Lytton ${ }^{\text {,cc\# }}$

${ }^{a}$ Drug Developmental Research Laboratory, Shionogi Pharmaceutical Research Center, Toyonaka, Osaka, Japan

${ }^{\mathrm{b}}$ State University of New York Downstate Health Science University, Brooklyn, NY, US

c Kings County Hospital, Brooklyn, NY, US

${ }^{\mathrm{d}}$ Neurosciences and Mental Health, The Hospital for Sick Children, Toronto, ON, Canada

e Institute of Biomedical Engineering, University of Toronto, Toronto, ON, Canada

${ }^{\mathrm{f}}$ Department of Physiology, University of Toronto, Toronto, ON, Canada

g Nathan Kline Institute for Psychiatric Research, Orangeburg, NY, US

* KS and LM contributed equally to this research

\# SAP and WWL contributed equally to this research

To whom correspondence should be addressed:

Steven A. Prescott

steve.prescott@sickkids.ca

William W. Lytton

bill1@neurosim.downstate.edu

Keywords: pain, spinal cord, dorsal horn, computer modeling, somatosensation 


\begin{abstract}
Pain-related sensory input is processed in the spinal cord before being relayed to the brain. That processing profoundly influences whether stimuli are correctly or incorrectly perceived as painful. Significant advances have been made in identifying the types of excitatory and inhibitory neurons that comprise the spinal dorsal horn (SDH), and there is some information about how neuron types are connected, but it remains unclear how the overall circuit processes sensory input. To explore SDH circuit function, we developed a computational model of the circuit that is tightly constrained by experimental data. Our model comprises conductance-based neuron models that reproduce the characteristic firing patterns of excitatory and inhibitory neurons. Excitatory neuron subtypes defined by calretinin, somatostatin, delta opioid receptor, protein kinase $\mathrm{C}$ gamma, or vesicular glutamate transporter 3 expression or by transient/central spiking/morphology, and inhibitory neuron subtypes defined by parvalbumin or dynorphin expression or by islet morphology were synaptically connected according to available qualitative data. Synaptic weights were adjusted to produce firing in projection neurons, defined by neurokinin-1 expression, matching experimentally measured responses to a range of mechanical stimulus intensities. Input to the circuit was provided by three types of afferents whose firing rates were also matched to experimental data. To validate our model, we ablated specific neuron types or applied other changes and compared model output with experimental data after equivalent manipulations. The resulting model provides a valuable tool for testing hypotheses in silico to plan novel experiments on SDH circuit dynamics and function.
\end{abstract}

\title{
Introduction
}

The spinal dorsal horn (SDH) plays a crucial role in processing somatosensory information, including pain. Sensory input conveyed to the SDH via primary afferent neurons is processed by local excitatory and inhibitory interneurons before being relayed to the brain (Todd, 2010). Superficial layers of the SDH, laminae I-II, receive noxious input responsible for nociceptive pain. Deeper layers receive predominantly innocuous tactile input but that input can be mistakenly perceived as painful if it is misprocessed (Prescott et al., 2014), resulting in mechanical allodynia, which is a common symptom in neuropathic pain conditions (Jensen and Finnerup, 2014). 
The classic Gate Control theory emphasized the importance of pain processing at the spinal level, particularly gating achieved through synaptic inhibition (Melzack and Wall, 1965). Much is now understood about those inhibitory mechanisms and about SDH circuits in general. Early efforts to classify SDH neurons by their spiking pattern, dendritic morphology and neurochemical phenotype (Grudt and Perl, 2002; Prescott and De Koninck, 2002; Ruscheweyh and Sandkühler, 2002; Yasaka et al., 2010) have been augmented more recently by molecular techniques that identify genetically-defined neuron types (Hantman et al., 2004; Duan et al., 2014; Petitjean et al., 2015, 2019; Abraira et al., 2017; Zhang et al., 2018; Peirs et al., 2020, 2021). Even genetic techniques only offer partial cell-type categorization. For example, $85 \%$ of calretinin neurons in laminae I-II are excitatory, overall nearly half of all SDH excitatory neurons, but the remaining $15 \%$ are inhibitory. Hence, extra steps must be taken to subdivide the group into neuron types with uniform functional properties (Peirs et al., 2021). These decades of research have naturally revealed the circuitry to be much more complex than originally envisioned by Melzack and Wall (for reviews see Peirs and Seal (2016); Lechner (2017)).

Despite this progress, many unknowns remain and making sense of available data is becoming more difficult. Indeed, impressive advances in basic pain research have not yet translated into improved clinical outcomes (Yekkirala et al., 2017). One way to take fuller advantage of available data - to identify patterns, reveal knowledge gaps, and help infer function - is through multiscale computational modeling (O’Leary et al., 2015; Lytton et al., 2017; Hunt et al., 2018). Compared with other areas of neuroscience, pain research has seen relatively scant computational investigation. Various aspects of SDH neuron and circuit function have been modeled (Britton and Skevington, 1989; Prescott et al., 2006; Le Franc and Le Masson, 2010; Arle et al., 2014; Zhang et al., 2014, 2015; Ratté et al., 2015; Balachandar and Prescott, 2018; Crodelle et al., 2019) but even the most sophisticated circuit models consider only a small fraction of available experimental data.

Here, we constructed a network model of lamina I-III that carefully incorporates the latest experimental data. Our conductance-based neuron models reproduce the characteristic spiking patterns of SDH neurons. The model also accounts for the differential input each neuron type receives from myelinated and unmyelinated primary afferents carrying information about low- and high-threshold mechanical input. Though synaptic connectivity patterns between each neuron type have been described, there is little quantitative information available about synaptic weights. We 
therefore tuned synaptic weights using a parameter space search with a genetic algorithm targeted to reproduce experimentally-observed projection neuron responses to primary afferent input patterns under specific stimulus conditions. The model was able to reproduce several experimental observations including the effects of selectively activating or inhibiting/ablating specific neuron types. This publicly-available, validated model will provide a resource for testing hypotheses in silico to predict experimental results, and for integrating new experimental data to further develop the model to obtain a more quantitative, comprehensive understanding of SDH function. In particular, multiscale modeling allows for linking changes at the molecular level (i.e. druggable targets) with emergent properties at the cellular and network levels that underlie clinical symptoms.

\section{Materials \& Methods}

\section{GENERAL INFORMATION}

We created a realistic spinal dorsal horn $(\mathrm{SDH})$ model that reproduced network output in rodent dorsal horn during mechanical stimulation under normal conditions, pathological conditions and after experimental ablation of specific spinal neuron types. Simulations were conducted with NEURON 8.0 (Hines and Carnevale, 2001; Carnevale and Hines, 2006) using NetPyNE 0.9.7 (Dura-Bernal et al., 2019), http://netpyne.org) with an integration step of $25 \mu$ s at temperature $37^{\circ} \mathrm{C}$. Model building, optimization and some of the analysis were also performed using NetPyNE 0.9.7. Additional analyses were performed in MATLAB R2021a (MathWorks). The network consisted of 409 neurons from 14 population subtypes. Five seconds of simulation time took 23.4 min to run on one processor with Intel 1.2 GHz Core m3. Parallel simulations were conducted with 10 cores. Approximately 2,000 network simulations and a similar number of single neuron simulations were run to develop this model.

Genetic algorithms were used to help tune ion channel densities to reproduce the spiking pattern of each neuron type, and to tune synaptic weights to reproduce projection neuron firing rates in response to a range of mechanical stimulus amplitudes (Neymotin et al. 2017; Dura-Bernal et al. 2015; Dura-Bernal et al. 2017). Ion channel conductances were tuned to provide tonic, delayed and initial burst firing. A-type potassium and delayed rectifier potassium (Kdr) channels in soma, hillock and dendrite were optimized with the genetic algorithm to obtain the reasonable interspike intervals. Conductances of $\mathrm{Kdr}$ channels and Hodgkin Huxley type sodium channels were optimized with the genetic algorithm so that experimentally-obtained spike train patterns were 
produced with appropriate current injection. For synaptic weights, the mean firing rate of pNK1 neurons after 50, 100 and $200 \mathrm{mN}$ mechanical stimuli were set as the fitness functions; synaptic weights between afferents and neurons and between presynaptic and postsynaptic neurons were optimized. We employed a custom genetic algorithm with tournament selection, uniform crossover, Gaussian mutation and generational replacement. Population size, maximum number of generations and mutation rate were set to 100,500 and 0.4 for all genetic algorithm fitting.

\section{DETAILS ABOUT NETWORK MODEL}

\section{CELL MODELS AND MORPHOLOGY}

The dorsal horn contains excitatory and inhibitory interneurons, and projection neurons. Starting from the morphology and conductance densities used by Zhang et al. (2014), parameters were optimized within a range of values constrained by the literature to match more closely with rodent experimental data for specific neuronal subtypes. All neurons consisted of soma, dendrites and axon initial segment (AIS). Membrane capacitance for all types of neurons was set to $1.0 \mu \mathrm{F} / \mathrm{cm}^{2}$. For excitatory neurons, two distinct firing patterns - delayed and transient firing - were implemented by adjusting conductance densities (Table 1). A-type potassium current $\left(\mathrm{K}_{\mathrm{A}}\right)$, which activates at subthreshold membrane potential and delays firing, was added to all excitatory neurons. In lamina II of the rodent spinal cord, delayed and transient firing are the major patterns seen in excitatory neurons, whereas tonic firing is most commonly observed in inhibitory neurons (Fig. 1) (Yasaka et al., 2010; Duan et al., 2014). We modeled transient central (eTrC) neurons with their main physiological characteristic of transient firing (Fig. 1A) which presents as brief firing within 100 msec of current onset at all amplitudes tested. Initial spike latency of delayed firing excitatory neurons decreased with increased current (Fig. 1B). Spike height of these neurons was $107 \mathrm{mV}$ from holding voltage, similar to the experimental value of $110 \mathrm{mV}$. Simulated tonic firing for inhibitory neurons was similar to the experimental firing profiles with 10, 30 and $130 \mathrm{pA}$ current injection (Fig. 1C). Ion channel conductance parameters are given in Table 1, except for the tonic firing pattern for which conductance values were the same as previously described by Zhang et al. (2014). 


\section{Table 1 Ion channels in excitatory, inhibitory and projection neurons}

\begin{tabular}{|c|c|c|c|c|}
\hline $\begin{array}{l}\text { Excitatory/inhibitory } \\
\text { interneuron population }\end{array}$ & Channel & $\begin{array}{l}\text { Conductance at dendrite } \\
(\mathrm{mho} / \mathrm{cm} 2)\end{array}$ & $\begin{array}{l}\text { Conductance } \\
\text { at soma }(\mathrm{mho} / \mathrm{cm} 2)\end{array}$ & $\begin{array}{l}\text { Conductance at AIS } \\
(\mathrm{mho} / \mathrm{cm} 2)\end{array}$ \\
\hline \multirow{7}{*}{$\begin{array}{l}\text { Delayed firing excitatory } \\
\text { neurons (ePKC } \gamma \text {, } \\
\text { eVGLUT3, eDOR, eSST, } \\
\text { eCR) }\end{array}$} & HH-type Na-1 & 0.0 & 0.08548 & 0.02375 \\
\hline & $\begin{array}{l}\text { HH-type } \quad \mathrm{Na}-2 \\
\text { (B_Na) }\end{array}$ & 0.0 & $1.652 \times 10^{-4}$ & 0.03 \\
\hline & HH-type $\mathrm{K}^{+}$ & 0.144 & 0.0043 & 0.304 \\
\hline & $\mathrm{K}_{\mathrm{A}}$ & $9.333 \times 10^{-4}$ & 0.0109 & 0.112 \\
\hline & $\mathrm{Kdr}$ & $9.60 \times 10^{-6}$ & $1.11 \times 10^{-4}$ & 0.01547 \\
\hline & $\mathrm{KCa}$ & 0.002 & 0.002 & 0.0 \\
\hline & Leak & $9.6 \times 10^{-7}$ & $9.6 \times 10^{-7}$ & $9.6 \times 10^{-7}$ \\
\hline \multirow{6}{*}{$\begin{array}{l}\text { Transient firing excitatory } \\
\text { neurons }(\mathrm{e} \operatorname{TrC})\end{array}$} & HH-type Na-1 & 0.0 & 0 & 0 \\
\hline & $\begin{array}{l}\text { HH-type } \quad \mathrm{Na}-2 \\
\text { (B_Na) }\end{array}$ & 0.0 & 0.3066 & 5.147 \\
\hline & $\mathrm{K}_{\mathrm{A}}$ & $1.584 \times 10^{-4}$ & 0.04957 & $5.0 \times 10^{-4}$ \\
\hline & $\mathrm{Kdr}$ & 0.2061 & $1.06 \times 10^{-5}$ & 0.2171 \\
\hline & $\mathrm{KCa}$ & 0.002 & 0.002 & 0.0 \\
\hline & Leak & $4.2 \times 10^{-5}$ & $4.2 \times 10^{-5}$ & $4.2 \times 10^{-5}$ \\
\hline \multirow{4}{*}{$\begin{array}{l}\text { Tonic firing inhibitory } \\
\text { neurons (iPV, iDYN and } \\
\text { iISLET) }\end{array}$} & HH-type Na-1 & 0.0 & 0.008 & 3.45 \\
\hline & $\begin{array}{l}\text { HH-type } \quad \mathrm{Na}-2 \\
\text { (B_Na) }\end{array}$ & 0.0 & 3.45 & 0.008 \\
\hline & $\mathrm{Kdr}$ & 0.034 & 0.0043 & 0.076 \\
\hline & Leak & $1.1 \times 10^{-5}$ & $1.1 \times 10^{-5}$ & $1.1 \times 10^{-5}$ \\
\hline \multirow[t]{7}{*}{ Projection neurons (pNK1) } & HH-type $\mathrm{Na}$ & 0.0 & 0.0 & 3.45 \\
\hline & HH-type K & 0.036 & 0.001075 & 0.076 \\
\hline & CaAN & $9.1 \times 10^{-5}$ & 0.0 & 0.0 \\
\hline & $\mathrm{CaL}$ & $3.0 \times 10^{-5}$ & $1.0 \times 10^{-4}$ & 0.0 \\
\hline & $\mathrm{KCa}$ & 0.001 & $1.0 \times 10^{-4}$ & 0.0 \\
\hline & $\mathrm{NaP}$ & 0.0 & $1.0 \times 10^{-4}$ & 0.0 \\
\hline & Leak & $4.2 \times 10^{-5}$ & $4.2 \times 10^{-5}$ & $4.2 \times 10^{-5}$ \\
\hline
\end{tabular}


AIS: axon initial segment. HH: Hodgkin Huxley-type channels. Kdr: delayed rectifier potassium channel. CaAN: slow calcium dependent cation channel. CaL: L-type high threshold calcium channel. KCa: slow calcium-dependent potassium channel. NaP: persistent sodium channel; $\mathrm{K}_{\mathrm{A}}$ : A-type potassium channel.

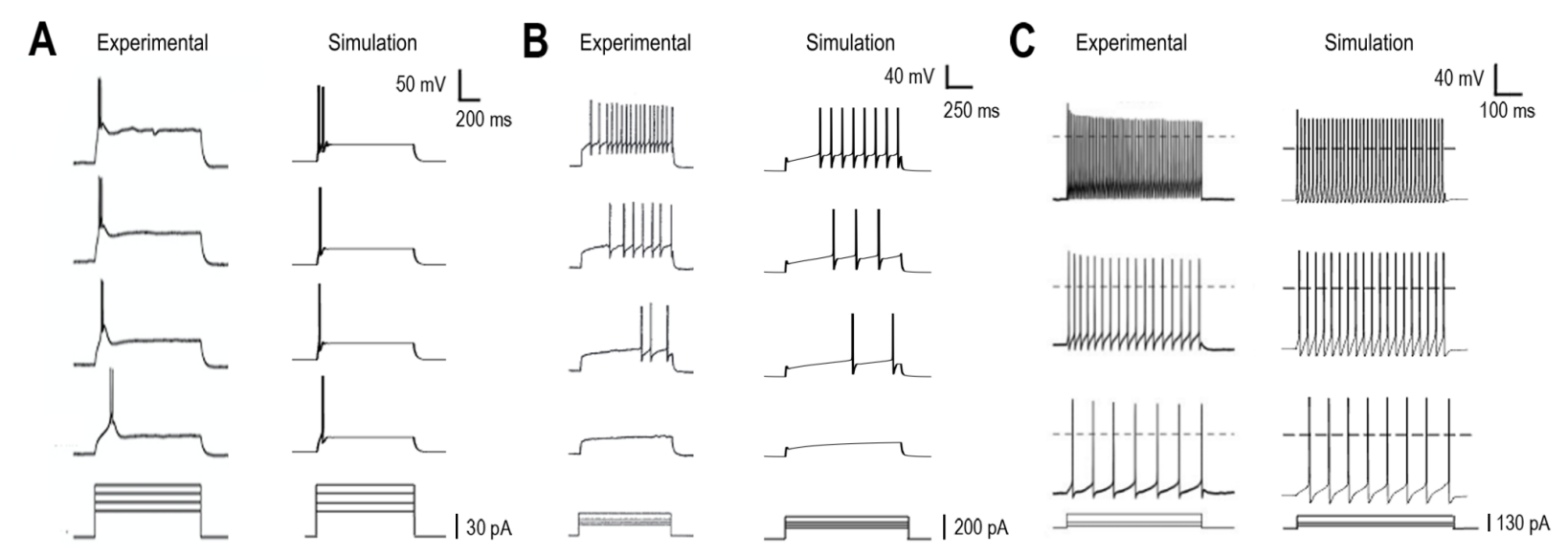

Figure 1. Firing patterns of isolated neurons under current clamp. (A) Transient firing of eTrC neurons compared to experimental data from (Duan et al., 2014). (B) Delayed firing seen in ePKC $\gamma$, eVGLUT3, eDOR, eSST, eCR neurons compared to experimental data from (Ruscheweyh and Sandkühler, 2002). (C) Tonic firing characteristic of iPV, iDYN, and iISLET neurons compared to experimental data from (Melnick et al., 2004).

Primary afferent neurons were not simulated as a conductance-based model; instead, they were treated as random (Poisson) input streams whose time-dependent firing rates in response to different mechanical stimulus intensities were set according to in vivo recordings from mice (Murthy et al., 2018; Walcher et al., 2018). Input streams representing $A \beta, A \delta$, and C fibers were synaptically connected to specific spinal neuron types (see below). C fibers were subdivided into peptidergic (C,TRPV1) and non-peptidergic (C,IB4) classes.

\section{SPINAL NEURON POPULATIONS}

In order to construct the network, inhibitory neurons were divided into three subtypes (designated by " $\mathrm{i}$ ") defined by their expression of parvalbumin (iPV) or dynorphin (iDYN), or by their islet morphology (iISLET). Some iPV neurons have islet morphology (Boyle et al., 2019), but in the model these two populations are implemented separately. Excitatory neurons were subdivided into six subtypes (designated by "e") defined by their expression of protein kinase $\mathrm{C}$ gamma (ePKC $\gamma$ ), vesicular glutamate transporter 3 (eVGLUT3), delta opioid receptor (eDOR), somatostatin (eSST), or calretinin $(\mathrm{eCR})$ or by their transient-spiking pattern $(\mathrm{e} \operatorname{TrC})$. Previous experiment has shown substantial overlap in gene expression between different excitatory subtypes (Fig. 2A). Specifically, these studies have highlighted the overlap between different excitatory neuron populations 
expressing SST: 35\% of VGLUT3-expressing neurons (Cheng et al., 2017), 63\% of PKC $\gamma$ expressing neurons (Gutierrez-Mecinas et al., 2016), 67\% of CR-expressing neurons (GutierrezMecinas et al., 2016), and 62\% of DOR-expressing neurons (Wang et al., 2018) have been shown to also express SST. Furthermore, Peirs et al. (2015) reported a 25\% and 7\% overlap between VGLUT3-expression with CR or PKC $\gamma$, respectively, with little to no overlap between CR and PKC $\gamma$ expression. In the SDH model, each of these neuronal subtypes are described as their own population, such that the eSST population is the subset of neurons which do not also express VGLUT3, PKC $\gamma, \mathrm{CR}$, or DOR. Some eSST and eCR neurons have vertical morphology with dorsoventral and rostrocaudal dendrites (Huang et al., 2018; Gutierrez-Mecinas et al., 2019). Projection $(\mathrm{p})$ neurons are defined by the expression of the neurokinin-1 (NK1) receptor and are henceforth referred to as pNK1 neurons (Todd et al., 2000). Choi et al. (2021) recently identified subtypes of projection neurons that do not express the NK1 receptor, but Browne et al. (2019) found that $83 \%$ of neurons projecting to the parabrachial nucleus were NK1 positive.

The model contains inputs from 200 afferent fibers $(20 \mathrm{~A} \beta, 20 \mathrm{~A} \delta, 80 \mathrm{C}$,IB4, and 80 C,TRPV1) and 209 spinal cord neurons (30 ePKC $\gamma, 4$ eVGLUT3, 30 eDOR, 10 eTrC, 15 eSST, 20 eCR, 15 iPV, 60 iDYN, 15 iISLET and 10 pNK1). The number of neurons and nociceptors were approximated based on the distribution of the diameters of afferent fibers measured in histological sections (Le Bars et al., 2001) and the proportion of each genetically defined neuron type (Häring et al., 2018).

\section{NETWORK CONNECTIVITY}

Neuronal connectivity of the SDH model (Fig. 2B,C) was based on recent reviews of experimental data (Peirs and Seal, 2016; Lechner, 2017), with additional connections and neurons based on more recent observations (Petitjean et al., 2015, 2019; Cheng et al., 2017; Wang et al., 2018; Smith et al., 2019). According to the previous reviews, eCR neurons were assumed to be the presynaptic neurons of eSST neurons, but eCR and eSST neurons are differentially involved in mechanical allodynia. Specifically, it was shown that eCR neurons selectively contribute to static allodynia following nerve injury (Duan et al., 2014; Petitjean et al., 2019), whereas eSST neurons contribute to both static and dynamic allodynia (Duan et al., 2014). Recent work has also demonstrated that some eCR neurons connect directly to the lamina I projection neurons (Petitjean et al., 2019; Smith et al., 2019). Based on these findings, eCR neurons were implemented separately from eSST and were 
connected directly to pNK1 neurons. Cheng et al. (2017) demonstrated that ablation of eVGLUT3 neurons attenuated dynamic allodynia but not static allodynia after nerve injury. Conversely, pharmacological inhibition of ePKC $\gamma$ neurons reduced both types of allodynia (Petitjean et al., 2015). These data suggest that eVGLUT3 neurons have synaptic connections with other neurons involved in dynamic mechanical stimuli in addition to their connections with ePKC $\gamma$ neurons. Based on these experimental observations, a connection between eVGLUT3 and eSST neurons was implemented in the model. eDOR neurons were also simulated and connected with eSST and eCR neurons based on observations that DOR agonists inhibited the activity of eSST neurons and increased the von Frey threshold (Wang et al., 2018). Also, it was demonstrated that A $\delta$ fibers exhibit monosynaptic or polysynaptic connections with eDOR and eSST, but not ePKC $\gamma$ neurons (Wang et al., 2018), and this is therefore reflected in the model circuitry. Variability in the spike trains of neurons across a population reflects the irregularity of input from primary afferent spike trains, as well as the unique connectivity formed between each neuron with its presynaptic input. Specifically, each neuron in the presynaptic population has a $20 \%$ probability of forming a connection with a neuron in the postsynaptic population; this connection probability dictates that each postsynaptic neuron will receive input from different presynaptic neurons and thus provide heterogeneity in spiking responses across the postsynaptic population.

\section{SYNAPSE MODELS}

Excitatory synaptic transmission was mediated by AMPA, NMDA and NK1 receptors whereas inhibitory synaptic transmission was mediated by $\mathrm{GABA}_{\mathrm{A}}$ and glycine receptors. Therefore, AMPA and NMDA receptors were implemented at each excitatory connection and $\mathrm{GABA}_{\mathrm{A}}$ and glycine receptors were implemented at each inhibitory connection, except: NMDA receptors were not included at the $\mathrm{C}-\mathrm{e}$ TrC, $\mathrm{C}-\mathrm{iDYN}, \mathrm{C}-\mathrm{iISLET}$ synapses; glycine receptors were not included in the iISLET-eTrC, iDYN-iISLET, and iISLET-iDYN synapses (Lu and Perl, 2003). NK1 receptors were included exclusively at the C,TRPV1-pNK1, eSST-pNK1, and eCR-pNK1 synapses based on experimental findings showing overlapping expression of substance P with SST (GutierrezMecinas et al., 2017) or CR (Gutierrez-Mecinas et al., 2019). The connectivity between each presynaptic and postsynaptic population is summarized in Fig. 2C. Synapses were modeled with the Exp2Syn mechanism, which is defined by rise and decay time constants, and scaled by a synaptic weight. Rise and decay time constants (ms) were: AMPA 0.1, 5; NMDA 2, 100; NK1 100, 
1000; $\mathrm{GABA}_{\mathrm{A}}$ 0.1, 20; glycine 0.1, 10. Inhibitory reversal potential (EANION) was $-70 \mathrm{mV}$ and excitatory reversal potential $\left(\mathrm{E}_{\mathrm{REV}}\right)$ was $0 \mathrm{mV}$. Synaptic weights for each presynaptic and postsynaptic connection were tuned as described in the Result section.
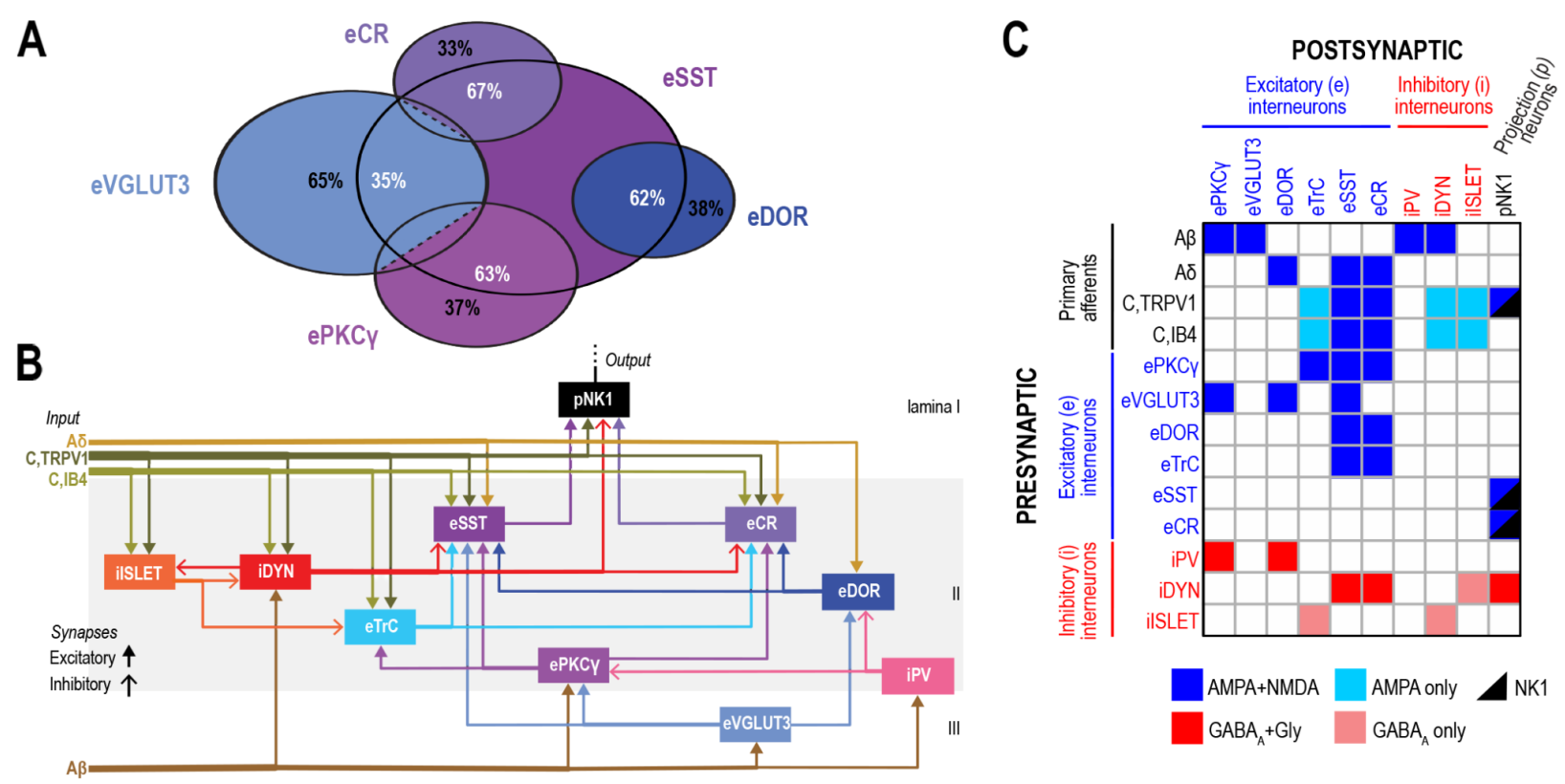

Figure 2. Synaptic connectivity of the SDH model. (A) Gene expression overlap among excitatory spinal neurons (overlap percents in with eSST in white based on eVGLUT3: Cheng et al., 2017; ePKC $\gamma$ and eCR: Guti errez-Mecinas et al., 2016; eDOR: Wang et al., 2018; eVGLUT3 with ePKC, eCR: Peirs et al., 2015). (B) Connectivity schematic; laminar locations indicated at right. (C) Connectivity matrix (CR: calretinin; DOR: delta opioid receptor; IB4: isolectin B4; NK1: neurokinin-1; PKC $\gamma$ : protein kinase C gamma; PV: parvalbumin; SST: somatostatin; DYN: dynorphin; $\operatorname{TrC}$ : transient central neurons; TRPV1: transient receptor potential cation channel subfamily V member 1; VGLUT3: vesicular glutamate transporter 3).

\section{Results}

The portion of the dorsal horn simulated consists of the superficial laminae I-III (Fig. 2B). Activation was via experimentally-known firing-rate correlates of stimulus input. One input population arrives via fibers of types $A \beta$, projecting to 4 neuron types, 2 inhibitory and 2 excitatory, in deep lamina II and in lamina III. Nociceptive A $\delta$ fibers arrive more superficially and activate 3 excitatory neuron types. Two sets of nociceptive $\mathrm{C}$ fibers also arrive in this superficial bundle and project together to 5 interneurons, 3 excitatory and 2 inhibitory, as well as projecting directly to the output neuron population: the pNK1 spinal projection neurons. These pNK1 neurons also receive inputs from 3 interneuron populations, 1 inhibitory and 2 excitatory. The latter 2 excitatory 
populations, somatostatin (eSST) and calretinin (eCR) neurons, are both network hubs and share most inputs (eCR lacks an input from eVGLUT3). Overall, our simulations were designed to demonstrate input-output relations: skin stimulation strength, measured in milliNewtons $(\mathrm{mN})$, produces activity in the network which results in projection neuron output.

\section{$\underline{\text { Responses to mechanical stimulation }}$}

We tuned synaptic weights in the SDH model by assessing firing rates of pNK1 neurons in response to mechanical stimuli of various intensities $(50,100$, and $200 \mathrm{mN})$. Mechanical stimuli were simulated at the input fiber level ( $\mathrm{A} \beta$, nociceptive $\mathrm{A} \delta$, and $\mathrm{C}$ fibers) by matching firing rates observed experimentally in response to different stimulus intensities (see Method section). At the intermediate intensity tested (100 mN; Fig. 3A), activation of $\mathrm{A} \beta$ (brown), A $\delta$ (gold), and C fibers (green) caused an increase in the firing rates of all excitatory and inhibitory neuron populations (except for iISLET neurons), and this resulted in an increase in pNK1 firing rates (black). Heterogeneity in the spike trains of neurons across a given population (Fig. 3A, raster plot) reflects the unique connectivity between each postsynaptic neuron with its presynaptic input (see Methods), as well as the randomness of spiking in primary afferents. At the weakest stimulus tested $(50 \mathrm{mN}$ : Fig. 3B, left), primarily $A \beta$ fibers were activated. This was sufficient to activate some excitatory and inhibitory interneurons (blue and red hues, respectively), but only caused modest activation of projection neurons; $40 \%$ of pNK1 neurons responded with 7-30 spikes over the 500 msec period. At $200 \mathrm{mN}$ stimulation (Fig. 3B, right), there was a greater contribution of input from A $\delta$ and Cfibers with no further increase in $A \beta$ input. Because of these differences in afferent input firing rates, slightly deeper neurons such as iPV and $\mathrm{ePKC} \gamma$ neurons, which receive input predominantly from $\mathrm{A} \beta$ fibers, showed only mild increases in firing as the stimulus intensity was increased from 50 to $200 \mathrm{mN}$. In contrast, neurons positioned more superficially, which receive significant direct input from $\mathrm{A} \delta$ and $\mathrm{C}$ fibers, showed substantial increases in firing as the stimulus intensity changed from 50 to $200 \mathrm{mN}$.

Figure 3C compares experimental firing rates from NK1 projection neurons during mechanical stimulation (Allard, 2019) with firing rates of pNK1 neurons in the SDH model after synaptic weights were tuned (Fig. 3D). As in most neural networks, there is great variability in responses across neurons of a given type, as well as within one neuron across multiple stimulus intensities. Variability in the model is due to randomness in the timing of input (afferent) spikes 
and to randomness in synaptic connectivity (i.e. each neuron in a presynaptic population has a $20 \%$ possibility of connecting to each neuron in the postsynaptic population). We therefore present a sample of pNK1 neuron firing rates as a function of stimulation strength and compare these firing rates with firing rates previously reported in mice. At each stimulus intensity tested, the model (white, $\mathrm{n}=10)$ reliably reproduced the firing rates of real (grey, $\mathrm{n}=32)$ projection neurons $(50 \mathrm{mN}$ : experiment $=1.09(0.27-4.88) \mathrm{spk} / \mathrm{s}$, model $=0.40(0-1.80) \mathrm{spk} / \mathrm{s} ; 100 \mathrm{mN}$ : experiment $=5.46$ $(0.48-11.39) \mathrm{spk} / \mathrm{s}$, model $=3.00(1.20-6) \mathrm{spk} / \mathrm{s} ; 200 \mathrm{mN}$ : experiment $=9.70(2.99-21.96) \mathrm{spk} / \mathrm{s}$, model $=11.30(7.40-14.20) \mathrm{spk} / \mathrm{s}$; expressed as median (IQR)).

To test that the SDH model could reproduce experimental findings (without any additional tuning of parameters), we compared the firing rates of pNK1 neurons before and after disinhibition caused by $\mathrm{GABA}_{A}$ and glycine receptor blockade (Fig. 4). We set the synaptic weights of all GABAergic and glycinergic connections to zero to simulate the blockade of these inhibitory receptors. Following inhibitory receptor blockade, the median firing rates of model pNK1 neurons increased by $14.8 \mathrm{spk} / \mathrm{s}$ at $10 \mathrm{mN}, 39.5 \mathrm{spk} / \mathrm{s}$ at $20 \mathrm{mN}, 64.2 \mathrm{spk} / \mathrm{s}$ at $50 \mathrm{mN}, 64.7 \mathrm{spk} / \mathrm{s}$ at $100 \mathrm{mN}$, and $61.20 \mathrm{spk} / \mathrm{s}$ at $200 \mathrm{mN}$. The firing rates of pNK1 neurons following inhibitory receptor blockade ranged from $0-85 \mathrm{spk} / \mathrm{s}$ across all stimulus intensities. These findings were comparable to the range of firing rates (10-170 spk/s) seen experimentally in lamina I projection neurons following the application of bicuculline and strychnine to block $\mathrm{GABA}_{\mathrm{A}}$ and glycine receptors (Allard, 2019). Importantly, following disinhibition, the firing rates of $\mathrm{pNK} 1$ at the lightest simulated intensities (10mN: $14.8(7.6-19) \mathrm{spk} / \mathrm{s} ; 20 \mathrm{mN}: 39.5$ (27.2-43.2) spk/s; expressed as median (IQR)), were consistent with experimental projection neuron firing rates in response to innocuous brush stimulation following inhibitory receptor blockade (brush: 30 (0-100) spk/s; Fig. 4, dashed line; Allard (2019)). Interestingly, inhibitory receptor blockade at $10 \mathrm{mN}$ resulted in an equivalent pNK1 firing rate to that seen at $200 \mathrm{mN}$ under normal stimulus conditions; consistent with disinhibition leading to mechanical allodynia. These findings validate the SDH model and further demonstrate its ability to simulate disinhibition in the context of allodynia and hyperalgesia. 

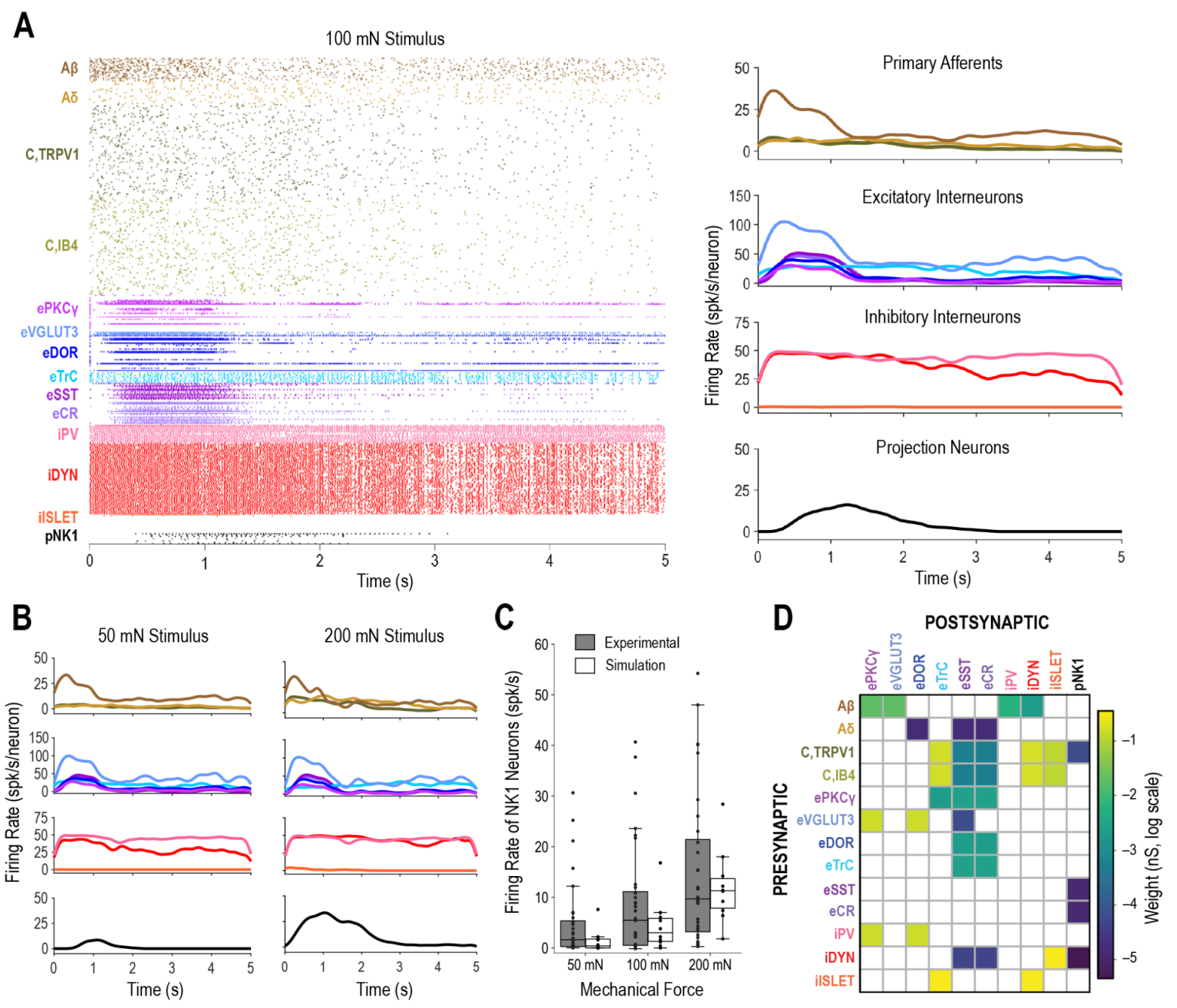

Figure 3. Fitting of SDH model to data. (A) Representative spike raster and firing rate histograms by population (100 $\mathrm{mN}$ ongoing stimulation; firing rate histograms based on $100 \mathrm{~ms}$ Gaussian kernel here and in following figures). (B) Firing rate histograms at 50 (left) and 200 (right) $\mathrm{mN}$ stimulation. (C) pNK1 projection neuron firing rates $(\mathrm{n}=10)$ compared to experiment ( $\mathrm{n}=32$ from Allard (2019)) (D) Synaptic weight matrix of the tuned SDH model. 


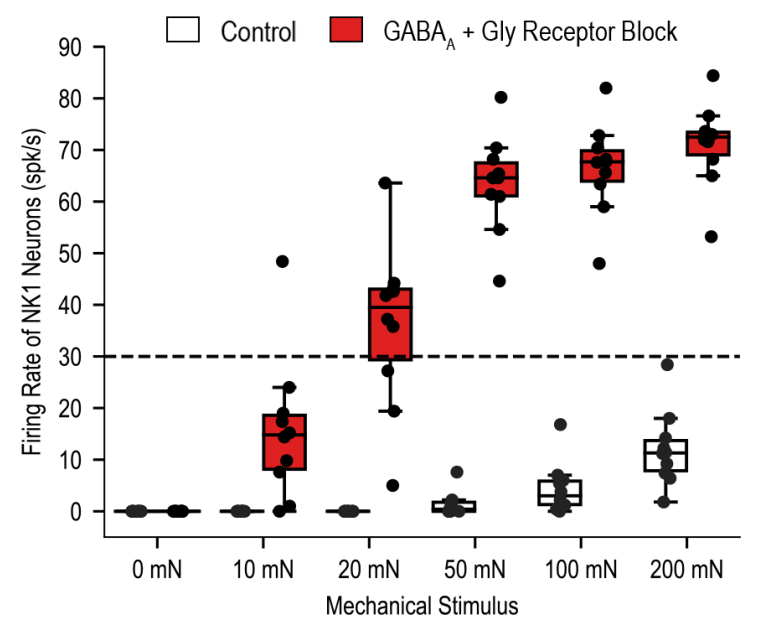

Figure 4. Network disinhibition $\left(\mathrm{GABA}_{\mathrm{A}}\right.$, glycine receptor blockade) compared to experiment (dashed line: median firing rate of lamina I projection neurons in response to brush stimulation following inhibitory receptor blockade (Allard, 2019)).

\section{$\underline{\text { Ablation of different spinal neuron populations }}$}

To further validate our model and make testable predictions for future work, we investigated changes in SDH circuit behaviour in response to ablation of different neuron types (Fig. 5). Previous experimental studies have examined the effect of ablating or silencing different spinal neuron populations, via genetic and pharmacological approaches, on changes in pain sensitivity in rodent models. Here, we used firing rates of pNK1 neurons as a biomarker indicating pain intensity in silico, where an increase or decrease in $\mathrm{pNK} 1$ firing rates indicates an increase or decrease in pain, respectively. This biomarker is consistent with previous experimental work which demonstrated that selective ablation of NK1 receptor positive projection neurons in lamina I attenuates allodynia and hyperalgesia in rodents (Mantyh et al., 1997; Nichols et al., 1999), as well as more recent work showing that their selective activation evokes behaviours associated with stress and anxiety (Choi et al., 2021).

In the context of mechanical allodynia, recent work by Petitjean et al. (2015) demonstrated that ablation of PV neurons by saporin decreased mechanical threshold (i.e. increased sensitivity) to von Frey stimulation in mice. Interestingly, this mechanical allodynia in PV-ablated mice was reversed following inhibition of $\mathrm{PKC} \gamma$ neuron activity by $\gamma \mathrm{V} 5-3$ application. To examine the effects of iPV ablation in the SDH model, we set the number of iPV neurons to zero while leaving all other aspects of the model unchanged, and measured the firing rate of $\mathrm{pNK} 1$ neurons. Ablation of $\mathrm{PPV}$ neurons increased pNK1 median firing rates by $154.25 \mathrm{x}$ from 0.4 to $61.70 \mathrm{spk} / \mathrm{s}$ at $50 \mathrm{mN}$ (Fig. 
$\mathbf{5 A b}$ ) and 6.19x from 11.30 to $70 \mathrm{spk} / \mathrm{s}$ at $200 \mathrm{mN}$ (Fig. 5A $\boldsymbol{h}$ ), indicating an increased pain response at these intensities compared to control conditions (Fig. 5Aa,g). ePKC $\gamma$ neurons were the excitatory spinal neurons most affected by the loss of iPV neurons, which drastically increased their firing rate (Fig. 5Ab, $\boldsymbol{h})$. In agreement with experimental findings (Petitjean et al., 2015), simultaneous ablation of $\mathrm{ePKC} \gamma$ neurons mitigated the increased $\mathrm{pNK} 1$ firing rate caused by ablation of $\mathrm{PVV}$ neurons (Fig. 5Ac,i). In our SDH model, iPV neurons inhibit ePKC $\gamma$ and eDOR neurons, but not eSST neurons, which offer an alternate path for low-threshold inputs to reach pNK1 neurons. Ablating eDOR neurons had little to no effect on the increased pNK1 firing following iPV ablation (Fig. 5Ad, j) whereas ablating eSST neurons decreased pNK1 neuron firing (Fig. 5Ae,k), but not as significantly as ePKC $\gamma$ ablation. Finally, ablating ePKC $\gamma$, eDOR, and eSST neurons blocked the increase in pNK1 firing rate caused by iPV ablation at both $50 \mathrm{mN}$ (Fig. 5Af) and $200 \mathrm{mN}$ (Fig. $\mathbf{5 A} \boldsymbol{l}$ ). Beyond demonstrating the importance of polysynaptic circuits for $A \beta$ input to reach pNK1 neurons, these results demonstrate that multiple routes exist within those circuits.

Figure 6 explores some of those additional routes. For instance, the eSST neurons that escape inhibition by iPV neurons are instead inhibited by iDYN neurons. Ablation of iDYN neurons increased pNK1 firing at $200 \mathrm{mN}$ (red, Fig. 6), but less so than might have been expected from the results of Duan et al. (2014) (see Discussion). Ablation of other major excitatory neurons populations (Fig. 6) - eCR (purple) and eVGLUT3 (blue) - reduced pNK1 firing rates at both 50 $\mathrm{mN}$ (not shown) and $200 \mathrm{mN}$, consistent with the results of Petitjean et al. (2019) and Cheng et al. (2017), respectively. These simulation results help validate our SDH model insofar as the model qualitatively reproduces several experimental observations without parameter re-tuning. 

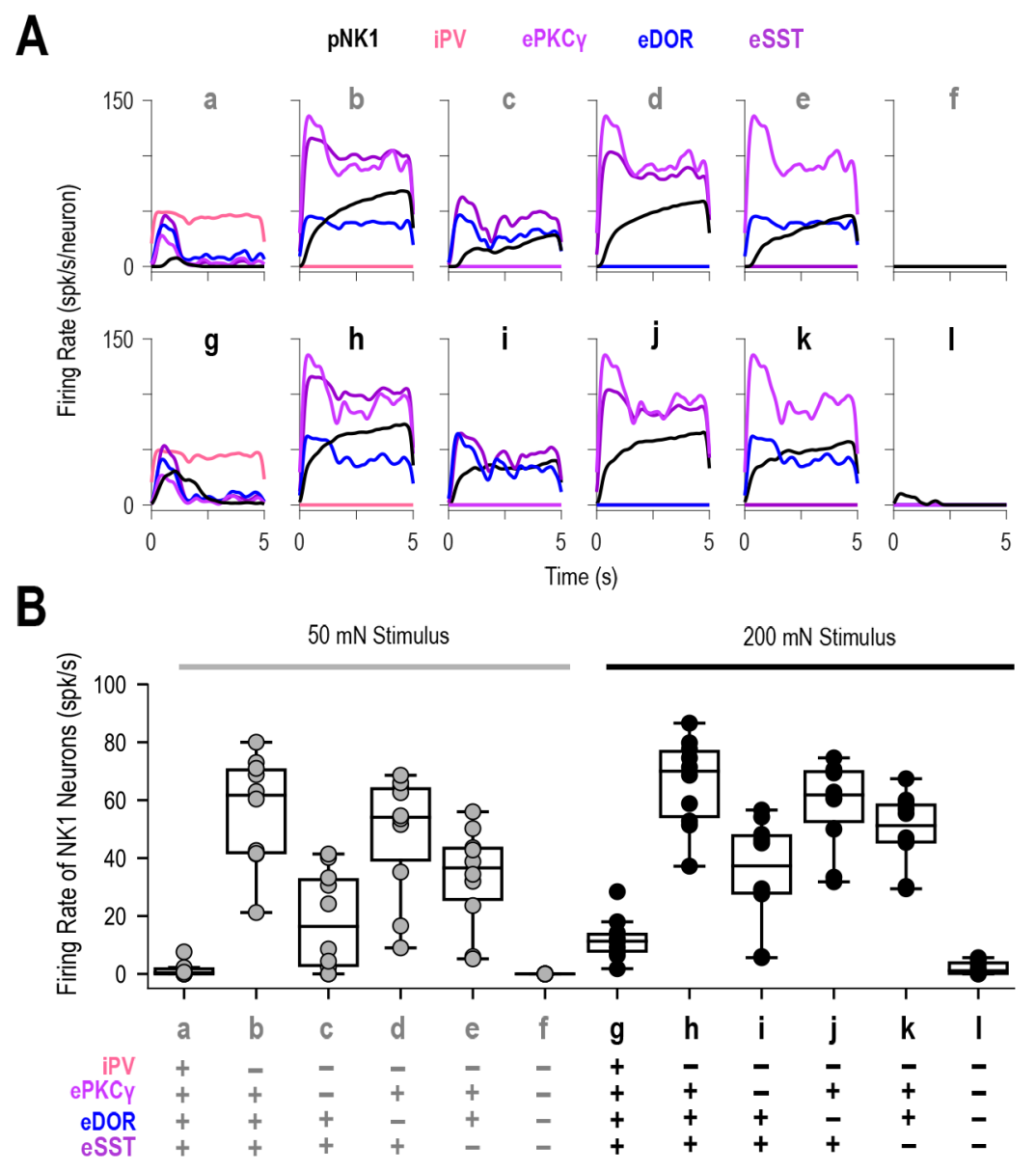

Figure 5. Effect of iPV neuron ablation on pNK1 firing depends on excitatory interneurons. (A) Firing rate histograms at $50 \mathrm{mN}(a-f)$ and $200 \mathrm{mN}(g-l)$ stimuli following ablation of specific populations (control: $a$, $g$; ablations of iPV:b, $h$; iPV $+\mathrm{ePKC} \gamma: c, i$; iPV+eDOR: $d, j$; iPV+eSST:e, $k$; iPV+ePKC $\gamma+\mathrm{eDOR}+\mathrm{eSST}: f, l)$. (B) Data summary with ablations indicated by minus signs.

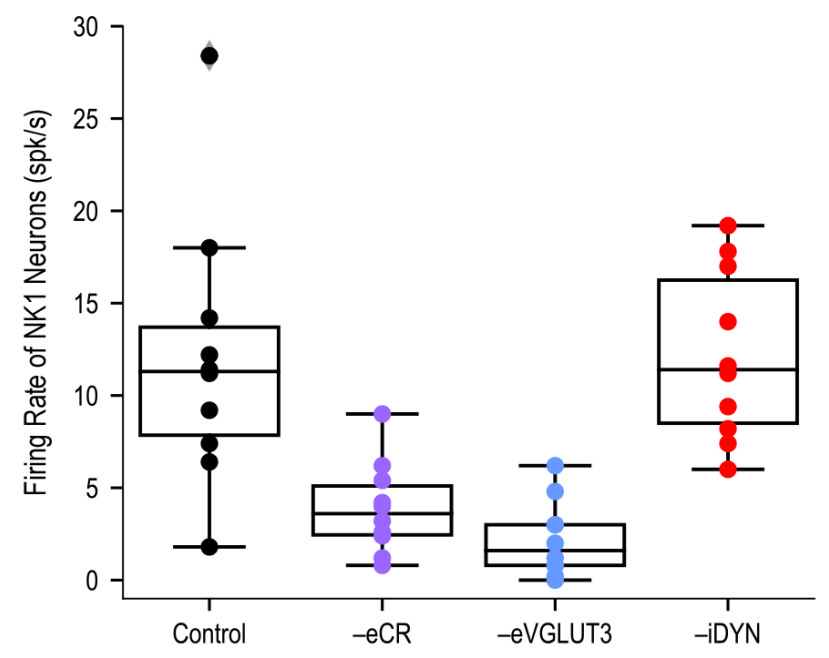

Figure 6. Effects of additional neuron type ablations on pNK1 response to $200 \mathrm{mN}$ stimulation. 


\section{Effect of chloride dysregulation on SDH circuit behaviour}

Synaptic inhibition is critical for proper processing of somatosensory stimuli in the SDH network. Following nerve injury, synaptic inhibition is reduced in the spinal cord such that innocuous "touch" signals are misperceived as painful. This so-called disinhibition in SDH can result from multiple different mechanisms including inhibitory receptor blockade (see Fig. 4) or chloride dysregulation, which results from downregulation of the potassium-chloride cotransporter 2 (KCC2), which in turn causes a depolarizing shift in the anion reversal potential ( $\left.\mathrm{E}_{\mathrm{ANION}}\right)$. Recent work has explored the effects of chloride dysregulation on SDH neurons (Keller et al., 2007; Lee et al., 2019), but the effect of these cellular-level changes on circuit-level function remains to be investigated. As such, using our model we investigated the effect of depolarizing $E_{\text {ANION }}$ from -70 to $-50 \mathrm{mV}$ on excitatoryinhibitory (E-I) balance in the SDH network and subsequent pNK1 firing rates. A global shift in $\mathrm{E}_{\mathrm{ANION}}$ (i.e. in all spinal neurons) resulted in increased firing in excitatory (blue hues) and inhibitory (red hues) spinal neuron populations, as well as a net increase in pNK1 (black) firing rates (Fig. 7A, center left column). This increase in pNK1 firing rates following a $20 \mathrm{mV}$ global shift in $\mathrm{E}_{\mathrm{ANION}}$ was consistent across all stimulus intensities (Fig. 7B, grey boxes).

We also applied the depolarizing $E_{A N I O N}$ shift individually to either excitatory or inhibitory spinal neurons. When applied only to excitatory neurons, the shift resulted in increased firing rates in excitatory spinal neuron populations (Fig. 7A, center right column) and a greater increase in pNK1 firing rates (blue boxes; Fig. 7B) compared to those seen during the global EANION shift (grey boxes; Fig. 7B). Conversely, the same shift in only inhibitory spinal neurons resulted in increased firing rates in inhibitory spinal neuron populations (Fig. 7A, rightmost column) and little to no change, or even a small decrease, in pNK1 firing rates across all stimulus intensities (Fig. 7B, red boxes). The difference in pNK1 firing rates (Fig. 7B) seen during an $\mathrm{E}_{\mathrm{ANION}}$ shift in all spinal neurons (grey) compared to only in excitatory neurons (blue) suggests that increased excitation of inhibitory spinal neurons may help mitigate the effect of increased excitation of excitatory spinal neurons during chloride dysregulation. Together with our validation work in $\mathrm{GABA}_{\mathrm{A}}$ and glycine receptor blockade (Fig. 4), these results further validate the ability of the SDH model to reproduce experiment findings related to disinhibition, as well as provide new insight into E-I balance following chloride dysregulation in the SDH network. 
A

A

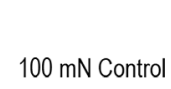

$\frac{\mathrm{E}_{\text {ANION }} \text { Shift from }-70 \mathrm{mV} \text { to }-50 \mathrm{mV}}{\text { All Cells } \quad \text { Excitatory Cells Inhibitory Cells }}$
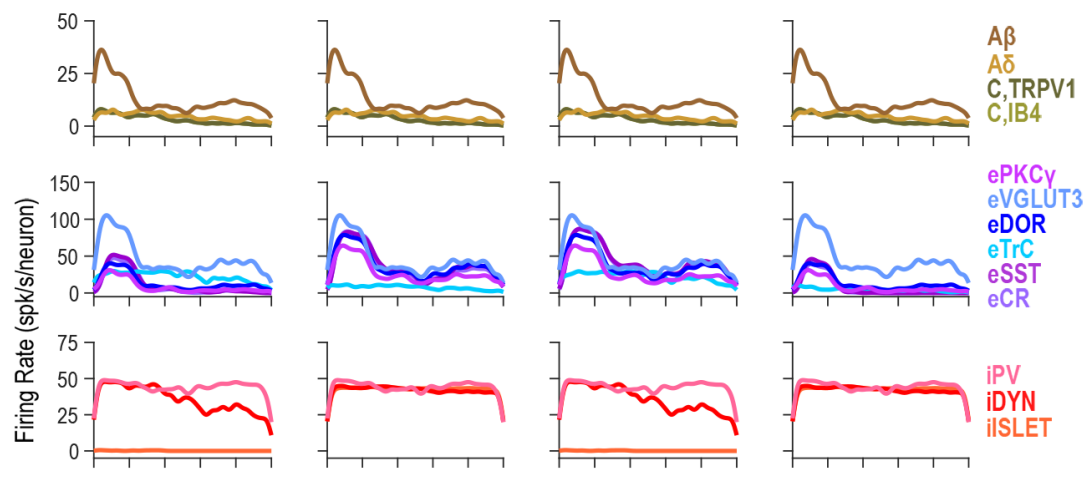

IPV

IISLET
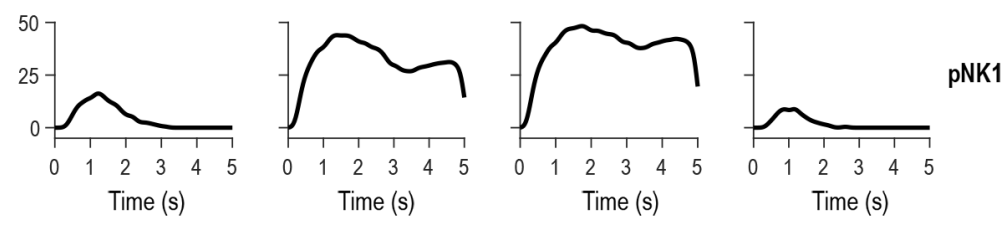

B

$\square$ Control

All Cells

Excitatory Cells

Inhibitory Cells

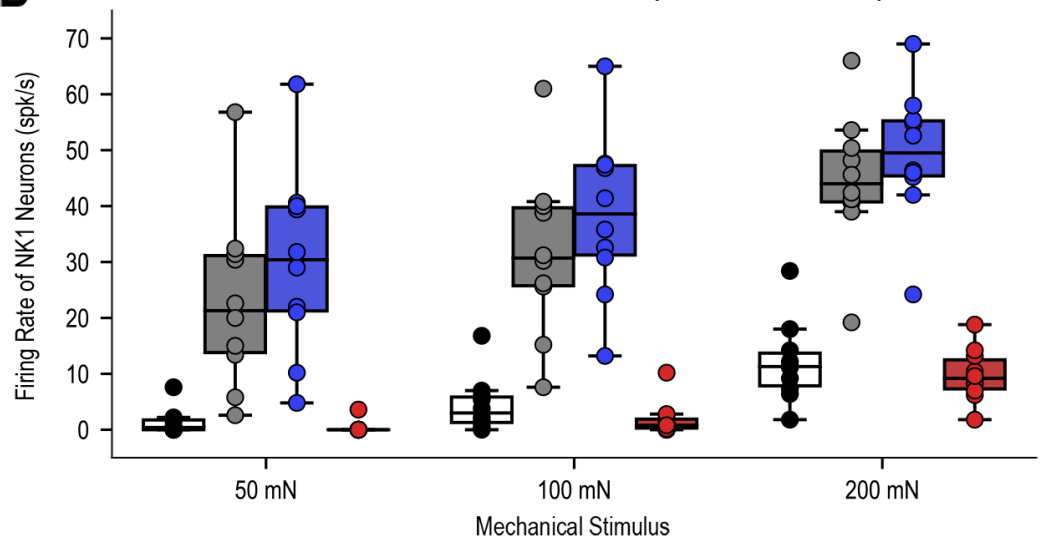

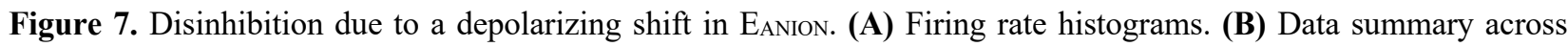
stimulus intensities.

\section{Effect of pharmacological manipulation of $K_{\mathrm{A}}$ channels}

A-type potassium $\left(\mathrm{K}_{\mathrm{A}}\right)$ channels regulate neuronal excitability at subthreshold potentials in many types of neuronsIn the spinal dorsal horn, Kv4.2 and Kv4.3 subunits are selectively expressed in excitatory neurons (Huang et al., 2005; Häring et al., 2018) and have been implicated in pain sensitivity (Chien et al., 2007; Duan et al., 2012). Based on the contribution of excitatory neurons to polysynaptic circuits that relay low-threshold input to pNK1 neurons, we hypothesized that $\mathrm{K}_{\mathrm{A}}$ channels represent another gating mechanism (beyond synaptic inhibition) that is liable to be important for mechanical allodynia. 
We therefore simulated the effect of enhancing or suppressing the conductance of $\mathrm{K}_{\mathrm{A}}$ channels in excitatory interneurons. Theoretically, inhibiting $\mathrm{K}_{\mathrm{A}}$ channel conductance should increase the firing rate of excitatory spinal interneurons and thus lead to an increase in pNK1 firing. As predicted, incremental blockade of these channels in the model led to a gradual increase in pNK1 firing at $200 \mathrm{mN}$ (Fig. 8). The median firing rate of pNK1 increased from $11.30 \mathrm{spk} / \mathrm{s}$ to $95.90 \mathrm{spk} / \mathrm{s}$ following complete blockade of $\mathrm{K}_{\mathrm{A}}$ channels $(0 \%$ of baseline; Fig. 8). The firing rate of pNK1 neurons following a decrease in $\mathrm{K}_{\mathrm{A}}$ conductance to $40 \%$ of its baseline was comparable to that after disinhibition caused by inhibitory receptor blockade at $200 \mathrm{mN}$ mechanical stimulus in our model (Fig. 4), suggesting that blockade of $K_{A}$ channels could lead to allodynia. The firing rate of excitatory neurons, including ePKC $\gamma$, eSST, eCR, eVGLUT3, and eDOR neurons, were also increased (data not shown). Conversely, at $160 \%$ of the baseline $\mathrm{K}_{\mathrm{A}}$ conductance, the median $\mathrm{pNK} 1$ firing rate decreased from $11.30 \mathrm{spk} / \mathrm{s}$ to $0.9 \mathrm{spk} / \mathrm{s}$ where they plateaued indicating a floor effect of $\mathrm{K}_{\mathrm{A}}$ enhancement.

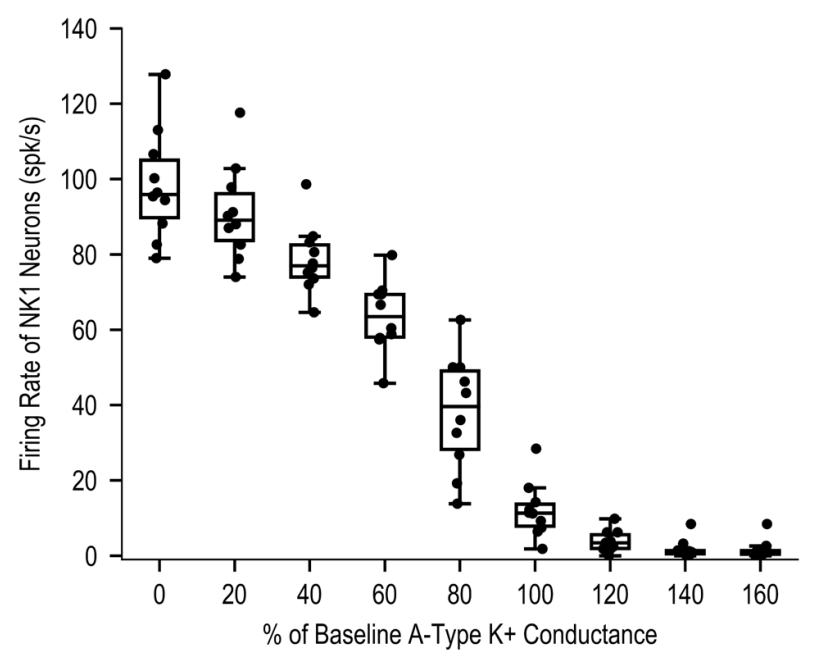

Figure 8. Effect of A-type potassium $\left(\mathrm{K}_{\mathrm{A}}\right)$ channel block $(0 \%)$ and enhancement on NK1 firing rate to $200 \mathrm{mN}$ mechanical stimulus.

\section{Effect of NK1 receptor blockade on disinhibition}

In this study we used an increase in pNK1 neuron firing as a biomarker for pain. NK1 receptor blockade has been shown to attenuate both mechanical allodynia and hyperalgesia in rodents (Cahill and Coderre, 2002). As such, we simulated the response NK1 receptor blockade in the SDH model (Fig. 9). Under $10 \mathrm{mN}$ control conditions (Fig. 9Aa), there was no firing in pNK1 neurons since 
the polysynaptic input from $A \beta$ fibers is blocked by spinal inhibitory mechanisms (Fig. 9Ab). At $200 \mathrm{mN}$, NK1 receptor blockade resulted in a decrease in pNK1 firing rates (Fig. 9Af) compared to control conditions (Fig. 9Ae). As previously shown, disinhibition unmasks significant A $\beta$ fibers input to pNK1 neurons (see Figs. 4 and 7). The increase in pNK1 firing rates caused by GABA and glycine receptor blockade (Fig. 9Ac,g) was dramatically attenuated by NK1 receptor blockade for $10 \mathrm{mN}$ (Fig. 9Ad ) and $200 \mathrm{mN}$ (Fig. 9A $\boldsymbol{h}$ ) stimulation, consistent with NK1 receptors contributing to mechanical allodynia and hyperalgesia, respectively. These findings are summarized in Fig. 9B and demonstrate the prediction that NK1 receptor blockade attenuates the effect of disinhibition.
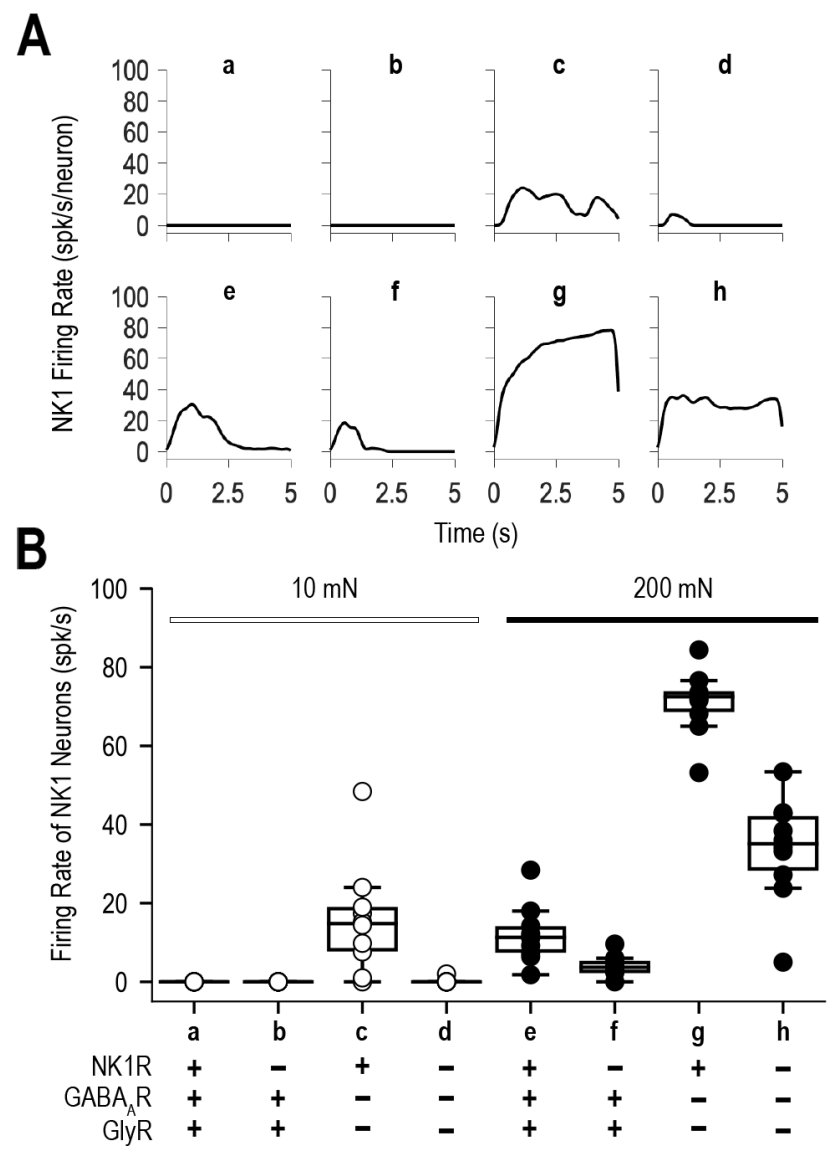

Figure 9. NK1 receptor blockade modulates the effect of disinhibition. (A) Firing rates $(10 \mathrm{mN} a-d ; 200 \mathrm{mN} e-h)$ with receptor blocks noted at bottom of B. (B) Data summary. 


\section{Discussion}

In this study, we built and validated a model of the spinal dorsal horn (SDH) network. Ion channel conductance densities of known SDH neuron types and synaptic weights were tuned so that pNK1 neuron firing rates, the network output, reproduced activity recorded during hind paw stimulation. Using these parameters, we reproduced experimental data of SDH changes following experimental manipulations: GABAA/glycine receptor blockade and ablation/silencing of specific neuron types. The validated model was then used to make experimentally testable predictions. A theme that emerges from these simulations is the importance of synaptic inhibition in gating transmission of low-threshold inputs via excitatory interneurons.

\section{Model construction and validation}

Accumulated information about intrinsic neuron properties (Fig. 1) and synaptic connectivity (Fig. 2C) were used to create the starting model. After tuning conductance densities to reproduce singleneuron current-clamp spiking patterns, we tuned synaptic weights (Fig. 3D) using experimental data reporting lamina I projection neuron responses to mechanical stimulation (Allard, 2019), and separate experimental data reporting primary afferent responses to comparable stimuli (Murthy et al., 2018; Walcher et al., 2018). This set of weights is not an exclusive parameter set due to solution degeneracy (see below) but, importantly, the resulting model successfully reproduced several other results.

To test model generalization to conditions it was not designed on, we simulated experimental manipulations that have been shown to modulate projection neuron firing, or that are inferred to do so given their impact on pain behavior. Our model quantitatively reproduced the elevated projection neuron firing (Fig. 4) observed by Allard (2019) after blocking GABA $\mathrm{A}$ and glycine receptors. It also reproduced the inferred increase in output caused by ablating iPV neurons and the mitigation of that effect by silencing ePKC $\gamma$ neurons (Fig. 5), consistent with Petitjean et al. (2015). This is also consistent with Boyle et al. (2019), though we did not simulate presynaptic inhibition. Our model also reproduced the inferred decrease in output caused by ablating eCR neurons (Fig. 6), consistent with Petitjean et al. (2019) (notwithstanding Duan et al. (2014)). Our model also confirmed the importance of eVGLUT3 neurons (Fig. 6), consistent with Cheng et al. (2017). Ablating iDYN neurons caused only a modest increase in output in our model (Fig. 6), 
contrary to the large effect reported by Duan et al. (2014). These successes serve to validate our model and the one inconsistency highlights biological redundancy (see below) rather than a fundamental flaw in the model.

\section{Biological insights emerging from the model}

Comparing results in Figures 5 and 6 suggests that inhibitory input from iPV neurons is more critical for gating low-threshold input to $\mathrm{pNK} 1$ neurons than inhibitory input from iDYN neurons. Ablating iDYN neurons in our model had a smaller effect than reported by Duan et al. (2014), which suggests that we underestimated the weight of iDYN synapses onto eSST and eCR neurons. This is possible because inhibition mediated by iDYN and iPV neurons is mostly redundant, with iDYN neurons inhibiting excitatory neurons immediately presynaptic to pNK1 neurons whereas iPV neurons inhibit excitatory further upstream (Fig. 2B). Based on this connectivity, iPV and iDYN neurons are each sufficient to gate the polysynaptic circuit relaying low-threshold inputs to pNK1 neurons. But this network structure predicts that ablating iPV neurons should not have a large effect (contrary to Petitjean et al. (2015)) when inhibitory input from iDYN neurons remains intact; the relative contribution of $\mathrm{PPV}$ and iDYN neurons may reflect the type of mechanical stimuli tested (see below). The data used to tune synaptic weights in Figure 3 did not allow us to resolve inhibition from iPV neurons from inhibition mediated by iDYN neurons. Nor can the source of inhibition be resolved from experiments blocking $\mathrm{GABA}_{\mathrm{A}} /$ glycine receptors or shifting $E_{\mathrm{ANION}}$ since inhibition is disrupted regardless of the type of presynaptic neurons.

For simulations in Figure 5, we silenced three different types of excitatory interneurons $\mathrm{ePKC} \gamma, \mathrm{eSST}$, and eDOR - alone and in combination to explore their contribution to driving pNK1 neuron firing after loss of inhibition from iPV neurons. Input relayed via ePKC $\gamma$ was largest, but eDOR neurons (also inhibited by iPV neurons) and eSST neurons (not inhibited by iPV neurons) also contributed. Simulation results in Figure 6 are also consistent with low-threshold input reaching pNK1 neurons via multiple pathways. Past experiments have emphasized the role of excitatory interneurons in mechanical allodynia (Torsney and MacDermott 2006; Santos et al. 2007; Wang et al. 2013; Duan et al. 2014; Christensen et al. 2016), but our results highlight the multiplicity of routes through this interconnected circuit. Different types of stimuli (e.g. punctate pressure vs brush) may preferentially utilize certain routes, making certain routes more or less important for static vs dynamic allodynia (Duan et al., 2014). It is also likely that different chronic 
pain states (e.g. inflammatory vs neuropathic) are associated with different pathological changes that disrupt sensory processing in different ways (Peirs et al., 2021).

When we blocked inhibition, the weakest stimulus tested $(10 \mathrm{mN})$ evoked $\mathrm{pNK} 1$ neuron firing comparable to that evoked under normal conditions by the strongest stimulus tested (200 $\mathrm{mN}$ ), consistent with allodynia caused by loss of spinal inhibition (see Prescott 2015 for review) (Fig. 4). Blocking GABA and glycine receptors (Fig. 4) caused disinhibition comparable to a large $\left(20 \mathrm{mV}\right.$ ) depolarizing shift in $E_{\mathrm{ANION}}$ (see Fig. 7), consistent with experiments by Lee and Prescott (2015). The depolarizing shift in $E_{\mathrm{ANION}}$ caused by KCC2 downregulation occurs in both excitatory and inhibitory interneurons (Lee et al., 2019) but simulating an $E_{\text {ANION }}$ shift selectively in excitatory interneurons caused more disinhibition than a global shift (Fig. 7), predicting that disinhibition of inhibitory neurons (which enhances inhibitory interneuron firing) can mitigate the effect of reduced chloride driving force. Our simulation results also predict that reducing the intrinsic excitability of excitatory interneurons (Fig. 8) or reducing substance P-NK1 receptor transmission from eSST and eCR neurons onto pNK1 neurons (Fig. 9) can reduce the activation of pNK1 neurons by lowthreshold inputs, independent of the inhibitory gating.

\section{Model limitations and outlook for future simulations}

Combinations of synaptic weights other than those depicted in Figure 3D can produce similar pNK1 neuron firing rates, as already discussed in the context of inhibitory input from iPV and iDYN neurons. This is because the model is relatively unconstrained for many reasons. First, quantitative information about many properties (e.g. the numbers of each neuron type, the probability of connection between neuron types, etc.) is unclear or altogether lacking. We have estimated such parameters based on the best available evidence. Second, even for parameters that can be tuned to reproduce experimental data such as neuron spiking patterns (see Fig. 1), there is significant heterogeneity within each neuron type - including quantitative variations in excitability as well as qualitative differences in spiking pattern (Balachandar and Prescott, 2018) - and there is also heterogeneity in the synaptic weights connecting neurons of particular types. Neither source of heterogeneity has been accounted for in the current model because relatively little is known about the underlying parameter distributions, or indeed if they can be fit by statistical models. That said, some heterogeneity is built into the model in the form of irregular primary afferent spike trains and random connectivity between neuron types. Third, complex systems are often degenerate, meaning 
equivalent output can be achieved on the basis of different parameter combinations (Edelman and Gally 2001; Prinz et al. 2004). Measuring many different aspects of cellular and network function can provide more constraints and a better fitted model, but this is fundamentally limited by biological degeneracy, which is to say there is no one set of parameters that uniquely describes the SDH network, even before considering variations that undoubtedly exist between each individual of a species. Despite these limitations, data-driven multiscale modeling can reveal important knowledge gaps to direct future experiments. Subsequent use of the resulting experimental data is then used to revise the model in an iterative manner to yield mechanistic insights that could not emerge from any particular data set considered in isolation. Indeed, increasing computing power and techniques emerging from artificial intelligence facilitate exploration of such high-dimensional data sets, as well as assisting in the model building itself.

In summary, we have built a model of the SDH circuit. The model was able to reproduce several experimental results, and was able to highlight and suggest explanations for apparent discrepancies in the experimental literature such as the role of iPV vs iDYN neurons. Integrating independent data sets into the model serves not only to strengthen the model, but will also lead to a more cohesive and quantitative understanding of pain processing. This will, we hope, help disentangle how the many pathological changes in the SDH caused by inflammation or nerve injury disrupt pain processing (Prescott et al., 2014) so that robust therapies can be more efficiently developed. 
Conflict of Interest: The authors declare no conflicts of interest.

Acknowledgments: This research was supported by New York State Spinal Cord Injury Research Grant (DOH01-C32250GG-3450000 2017-2022; SD, WL); NIH NIMH R01MH086638 (WL); NIH U24EB028998 (SD), NSF 1904444-1042C (SD, WL); CIHR Foundation Grant 167276 (SAP); Restracomp Scholarship from the Hospital for Sick Children (LM).

Author Contributions: KS, LM, SD, SAP, and WWL conceived and designed the study. KS and LM conducted simulations and analyzed data. KS, LM, SD, SAP and WWL wrote the final paper. 


\section{References}

Abraira VE et al. (2017) The Cellular and Synaptic Architecture of the Mechanosensory Dorsal Horn. Cell 168:295-310.e19.

Allard J (2019) Physiological properties of the lamina I spinoparabrachial neurons in the mouse. J Physiol 597:2097-2113.

Arle JE, Carlson KW, Mei L, Iftimia N, Shils JL (2014) Mechanism of dorsal column stimulation to treat neuropathic but not nociceptive pain: analysis with a computational model. Neuromodulation 17:642-655.

Balachandar A, Prescott SA (2018) Origin of heterogeneous spiking patterns from continuously distributed ion channel densities: a computational study in spinal dorsal horn neurons. J Physiol 596:1681-1697.

Boyle KA, Gradwell MA, Yasaka T, Dickie AC, Polgár E, Ganley RP, Orr DPH, Watanabe M, Abraira VE, Kuehn ED, Zimmermann AL, Ginty DD, Callister RJ, Graham BA, Hughes DI (2019) Defining a spinal microcircuit that gates myelinated afferent input: Implications for tactile allodynia. Cell Reports 28:526-540.e6.

Britton NF, Skevington SM (1989) A mathematical model of the gate control theory of pain. J Theor Biol 137:91-105.

Browne TJ, Smith KM, Gradwell MA, Iredale JA, Dayas CV, Callister RJ, Hughes DI, Graham BA (2019) Spinoparabrachial projection neurons form distinct classes in the mouse dorsal horn. Pain.

Cahill CM, Coderre TJ (2002) Attenuation of hyperalgesia in a rat model of neuropathic pain after intrathecal pre- or post-treatment with a neurokinin-1 antagonist. Pain 95:277-285.

Carnevale NT, Hines ML (2006) The NEURON Book. New York: Cambridge University Press.

Cheng L, Duan B, Huang T, Zhang Y, Chen Y, Britz O, Garcia-Campmany L, Ren X, Vong L, Lowell BB, Goulding M, Wang Y, Ma Q (2017) Identification of spinal circuits involved in touch-evoked dynamic mechanical pain. Nat Neurosci 20:804-814.

Chien L-Y, Cheng J-K, Chu D, Cheng C-F, Tsaur M-L (2007) Reduced expression of A-type potassium channels in primary sensory neurons induces mechanical hypersensitivity. $\mathrm{J}$ Neurosci 27:9855-9865.

Choi S, Hachisuka J, Brett M, Magee A, Koerber H, Ross S, Ginty D (2021) Parallel ascending spinal pathways for affective touch and pain. The Journal of Pain 578:258-263.

Crodelle J, Piltz SH, Hagenauer MH, Booth V (2019) Modeling the daily rhythm of human pain processing in the dorsal horn. PLOS Computational Biology 15:e1007106.

Duan B, Cheng L, Bourane S, Britz O, Padilla C, Garcia-Campmany L, Krashes M, Knowlton W, 
Velasquez T, Ren X, Ross S, Lowell BB, Wang Y, Goulding M, Ma Q (2014) Identification of spinal circuits transmitting and gating mechanical pain. Cell 159:1417-1432.

Duan K-Z, Xu Q, Zhang X-M, Zhao Z-Q, Mei Y-A, Zhang Y-Q (2012) Targeting A-type K channels in primary sensory neurons for bone cancer pain in a rat model. Pain 153:562-574.

Dura-Bernal S, Suter BA, Gleeson P, Cantarelli M, Quintana A, Rodriguez F, Kedziora DJ, Chadderdon GL, Kerr CC, Neymotin SA, McDougal RA, Hines M, Shepherd GM, Lytton WW (2019) NetPyNE, a tool for data-driven multiscale modeling of brain circuits. eLife 8:e44494.

Edelman GM, Gally JA (2001) Degeneracy and complexity in biological systems. Proc Natl Acad Sci U S A 98:13763-13768.

Grudt TJ, Perl ER (2002) Correlations between neuronal morphology and electrophysiological features in the rodent superficial dorsal horn. The Journal of Physiology 540:189-207.

Gutierrez-Mecinas M, Bell AM, Marin A, Taylor R, Boyle KA, Furuta T, Watanabe M, Polgár E, Todd AJ (2017) Preprotachykinin A is expressed by a distinct population of excitatory neurons in the mouse superficial spinal dorsal horn including cells that respond to noxious and pruritic stimuli. Pain 158:440-456.

Gutierrez-Mecinas M, Davis O, Polgár E, Shahzad M, Navarro-Batista K, Furuta T, Watanabe M, Hughes DI, Todd AJ (2019) Expression of Calretinin Among Different Neurochemical Classes of Interneuron in the Superficial Dorsal Horn of the Mouse Spinal Cord. Neuroscience 398:171-181.

Gutierrez-Mecinas M, Furuta T, Watanabe M, Todd AJ (2016) A quantitative study of neurochemically defined excitatory interneuron populations in laminae I-III of the mouse spinal cord. Mol Pain 12.

Hantman AW, van den Pol AN, Perl ER (2004) Morphological and physiological features of a set of spinal substantia gelatinosa neurons defined by green fluorescent protein expression. J Neurosci 24:836-842.

Häring M, Zeisel A, Hochgerner H, Rinwa P, Jakobsson JET, Lönnerberg P, La Manno G, Sharma N, Borgius L, Kiehn O, Lagerström MC, Linnarsson S, Ernfors P (2018) Neuronal atlas of the dorsal horn defines its architecture and links sensory input to transcriptional cell types. Nat Neurosci 21:869-880.

Hines ML, Carnevale NT (2001) NEURON: a tool for neuroscientists. Neuroscientist 7:123-135.

Huang H-Y, Cheng J-K, Shih Y-H, Chen P-H, Wang C-L, Tsaur M-L (2005) Expression of A-type $\mathrm{K}$ channel alpha subunits $\mathrm{Kv} 4.2$ and $\mathrm{Kv} 4.3$ in rat spinal lamina II excitatory interneurons and colocalization with pain-modulating molecules. Eur J Neurosci 22:1149-1157.

Huang J, Polgár E, Solinski HJ, Mishra SK, Tseng P-Y, Iwagaki N, Boyle KA, Dickie AC, Kriegbaum MC, Wildner H, Zeilhofer HU, Watanabe M, Riddell JS, Todd AJ, Hoon MA 
(2018) Circuit dissection of the role of somatostatin in itch and pain. Nat Neurosci 21:707716.

Hunt CA, Erdemir A, Lytton WW, Mac Gabhann F, Sander EA, Transtrum MK, Mulugeta L (2018) The Spectrum of Mechanism-Oriented Models and Methods for Explanations of Biological Phenomena. Processes 6:56.

Jensen TS, Finnerup NB (2014) Allodynia and hyperalgesia in neuropathic pain: clinical manifestations and mechanisms. Lancet Neurol 13:924-935.

Keller AF, Beggs S, Salter MW, De Koninck Y (2007) Transformation of the output of spinal lamina I neurons after nerve injury and microglia stimulation underlying neuropathic pain. Mol Pain 3:27.

Le Bars D, Gozariu M, Cadden SW (2001) Animal models of nociception. Pharmacol Rev 53:597652.

Lechner SG (2017) An update on the spinal and peripheral pathways of pain signalling. Neuroforum $23: 3$.

Lee KY, Prescott SA (2015) Chloride dysregulation and inhibitory receptor blockade yield equivalent disinhibition of spinal neurons yet are differentially reversed by carbonic anhydrase blockade. Pain 156:2431-2437.

Lee KY, Ratté S, Prescott SA (2019) Excitatory neurons are more disinhibited than inhibitory neurons by chloride dysregulation in the spinal dorsal horn. eLife 8:e49753.

Le Franc Y, Le Masson G (2010) Multiple Firing Patterns in Deep Dorsal Horn Neurons of the Spinal Cord: Computational Analysis of Mechanisms and Functional Implications. Journal of Neurophysiology 104:1978-1996.

Lu Y, Perl ER (2003) A specific inhibitory pathway between substantia gelatinosa neurons receiving direct C-fiber input. J Neurosci 23:8752-8758.

Lytton WW, Arle J, Bobashev G, Ji S, Klassen TL, Marmarelis VZ, Schwaber J, Sherif MA, Sanger TD (2017) Multiscale modeling in the clinic: diseases of the brain and nervous system. Brain Inform 4:219-230.

Mantyh PW, Rogers SD, Honore P, Allen BJ, Ghilardi JR, Li J, Daughters RS, Lappi DA, Wiley RG, Simone DA (1997) Inhibition of hyperalgesia by ablation of lamina I spinal neurons expressing the substance P receptor. Science 278:275-279.

Melnick IV, Santos SFA, Szokol K, Szûcs P, Safronov BV (2004) Ionic basis of tonic firing in spinal substantia gelatinosa neurons of rat. J Neurophysiol 91:646-655.

Melzack R, Wall PD (1965) Pain mechanisms: a new theory. Science 150:971-979.

Murthy SE, Loud MC, Daou I, Marshall KL, Schwaller F, Kühnemund J, Francisco AG, Keenan 
WT, Dubin AE, Lewin GR, Patapoutian A (2018) The mechanosensitive ion channel Piezo2 mediates sensitivity to mechanical pain in mice. Sci Transl Med 462:eaat9897.

Nichols ML, Allen BJ, Rogers SD, Ghilardi JR, Honore P, Luger NM, Finke MP, Li J, Lappi DA, Simone DA, Mantyh PW (1999) Transmission of chronic nociception by spinal neurons expressing the substance $P$ receptor. Science 286:1558-1561.

O’Leary T, Sutton AC, Marder E (2015) Computational models in the age of large datasets. Curr Opin Neurobiol 32:87-94.

Peirs C, Dallel R, Todd AJ (2020) Recent advances in our understanding of the organization of dorsal horn neuron populations and their contribution to cutaneous mechanical allodynia. $\mathrm{J}$ Neural Transm 127:505-525.

Peirs C, Seal RP (2016) Neural circuits for pain: Recent advances and current views. Science 354:578-584.

Peirs C, Williams S-PG, Zhao X, Arokiaraj CM, Ferreira DW, Noh M-C, Smith KM, Halder P, Corrigan KA, Gedeon JY, Lee SJ, Gatto G, Chi D, Ross SE, Goulding M, Seal RP (2021) Mechanical allodynia circuitry in the dorsal horn is defined by the nature of the injury. Neuron 109:73-90.e7.

Peirs C, Williams S-PG, Zhao X, Walsh CE, Gedeon JY, Cagle NE, Goldring AC, Hioki H, Liu Z, Marell PS, Seal RP (2015) Dorsal horn circuits for persistent mechanical pain. Neuron 87:797812.

Petitjean H, Bourojeni FB, Tsao D, Davidova A, Sotocinal SG, Mogil JS, Kania A, Sharif-Naeini R (2019) Recruitment of spinoparabrachial neurons by dorsal horn calretinin neurons. Cell Rep 28:1429-1438.e4.

Petitjean H, Pawlowski SA, Fraine SL, Sharif B, Hamad D, Fatima T, Berg J, Brown CM, Jan LY, Ribeiro-da-Silva A, Braz JM, Basbaum AI, Sharif-Naeini R (2015) Dorsal horn parvalbumin neurons are gate-keepers of touch-evoked pain after nerve injury. Cell Reports $13: 1246-1257$.

Prescott SA (2015) Chapter Twelve - Synaptic Inhibition and Disinhibition in the Spinal Dorsal Horn. In: Progress in Molecular Biology and Translational Science (Price TJ, Dussor G, eds), pp 359-383. Academic Press.

Prescott SA, De Koninck Y (2002) Four cell types with distinctive membrane properties and morphologies in lamina I of the spinal dorsal horn of the adult rat. J Physiol 539:817-836.

Prescott SA, Ma Q, De Koninck Y (2014) Normal and abnormal coding of somatosensory stimuli causing pain. Nat Neurosci 17:183-191.

Prescott SA, Sejnowski TJ, De Koninck Y (2006) Reduction of anion reversal potential subverts the inhibitory control of firing rate in spinal lamina I neurons: towards a biophysical basis for neuropathic pain. Mol Pain 2:32. 
Ratté S, Lankarany M, Rho Y-A, Patterson A, Prescott SA (2015) Subthreshold membrane currents confer distinct tuning properties that enable neurons to encode the integral or derivative of their input. Front Cell Neurosci 8:452.

Ruscheweyh R, Sandkühler J (2002) Lamina-specific membrane and discharge properties of rat spinal dorsal horn neurones in vitro. J Physiol 541:231-244.

Santos SFA, Rebelo S, Derkach VA, Safronov BV (2007) Excitatory interneurons dominate sensory processing in the spinal substantia gelatinosa of rat. J Physiol 581:241-254.

Smith KM, Browne TJ, Davis OC, Coyle A, Boyle KA, Watanabe M, Dickinson SA, Iredale JA, Gradwell MA, Jobling P, Callister RJ, Dayas CV, Hughes DI, Graham BA (2019) Calretinin positive neurons form an excitatory amplifier network in the spinal cord dorsal horn. eLife 8:e49190.

Todd AJ (2010) Neuronal circuitry for pain processing in the dorsal horn. Nat Rev Neurosci $11: 823-836$.

Todd AJ, McGill MM, Shehab SA (2000) Neurokinin 1 receptor expression by neurons in laminae I, III and IV of the rat spinal dorsal horn that project to the brainstem. Eur J Neurosci 12:689700 .

Torsney C, MacDermott AB (2006) Disinhibition opens the gate to pathological pain signaling in superficial neurokinin 1 receptor-expressing neurons in rat spinal cord. J Neurosci 26:18331843.

Walcher J, Ojeda-Alonso J, Haseleu J, Oosthuizen MK, Rowe AH, Bennett NC, Lewin GR (2018) Specialized mechanoreceptor systems in rodent glabrous skin. J Physiol 596:4995-5016.

Wang D, Tawfik VL, Corder G, Low SA, François A, Basbaum AI, Scherrer G (2018) Functional divergence of delta and mu opioid receptor organization in CNS pain circuits. Neuron 98:90108.e5.

Wang X, Zhang J, Eberhart D, Urban R, Meda K, Solorzano C, Yamanaka H, Rice D, Basbaum AI (2013) Excitatory superficial dorsal horn interneurons are functionally heterogeneous and required for the full behavioral expression of pain and itch. Neuron 78:312-324.

Yasaka T, Tiong SYX, Hughes DI, Riddell JS, Todd AJ (2010) Populations of inhibitory and excitatory interneurons in lamina II of the adult rat spinal dorsal horn revealed by a combined electrophysiological and anatomical approach. Pain 151:475-488.

Yekkirala AS, Roberson DP, Bean BP, Woolf CJ (2017) Breaking barriers to novel analgesic drug development. Nat Rev Drug Discov 16:545-564.

Zhang TC, Janik JJ, Grill WM (2014) Modeling effects of spinal cord stimulation on wide-dynamic range dorsal horn neurons: influence of stimulation frequency and GABAergic inhibition. J Neurophysiol 112:552-567. 
bioRxiv preprint doi: https://doi.org/10.1101/2021.06.09.447785; this version posted June 10, 2021. The copyright holder for this preprint (which was not certified by peer review) is the author/funder. All rights reserved. No reuse allowed without permission.

Zhang TC, Janik JJ, Peters RV, Chen G, Ji R-R, Grill WM (2015) Spinal sensory projection neuron responses to spinal cord stimulation are mediated by circuits beyond gate control. $\mathrm{J}$ Neurophysiol 114:284-300.

Zhang Y, Liu S, Zhang Y-Q, Goulding M, Wang Y-Q, Ma Q (2018) Timing mechanisms underlying gate control by feedforward inhibition. Neuron 99:941-955.e4. 